\title{
Critical Comparison between Modified Monier-Williams and Electrochemical Methods to Determine Sulfite in Aqueous Solutions
}

\author{
C. Montes, ${ }^{1}$ J. H. Vélez, ${ }^{1}$ G. Ramírez, ${ }^{2}$ M. Isaacs, ${ }^{2}$ R. Arce, ${ }^{1}$ and M. J. Aguirre ${ }^{1}$ \\ ${ }^{1}$ Departamento de Química de Los Materiales, Facultad de Química y Biología, Universidad de Santiago de Chile (USACH), \\ Avenida L.B. O’Higgins 3363, Estación Central, Santiago 9170022, Chile \\ ${ }^{2}$ Departamento de Química Inorgánica, Facultad de Química, Pontificia Universidad Católica de Chile, Vicuña Mackenna 4860, \\ Santiago 7820536, Chile
}

Correspondence should be addressed to G. Ramírez, gramirezj@uc.cl

Received 3 October 2011; Accepted 2 November 2011

Academic Editors: C. Mateo and I. Shibata

Copyright () 2012 C. Montes et al. This is an open access article distributed under the Creative Commons Attribution License, which permits unrestricted use, distribution, and reproduction in any medium, provided the original work is properly cited.

\begin{abstract}
In the present work, known concentration of sulfite aqueous solutions in the presence and absence of gallic acid was measured to corroborate the validity of modified Monier-Williams method. Free and bound-sulfite was estimated by differential pulse voltammetry. To our surprise, the modified Monier-Williams method (also known as aspiration method) showed to be very inaccurate for free-sulfite, although suitable for bound-sulfite determination. The differential pulse approach, using the standard addition method and a correction coefficient, proved to be swift, cheap, and very precise and accurate.
\end{abstract}

\section{Introduction}

Undoubtedly sulfur dioxide is the most widely spread additive in winemaking and essential as well. Antioxidant [1], antioxidasic [2], and antimicrobial [3,4] effects turn sulfur dioxide into a practically essential additive not only in winemaking but also in other food production [5]. Sulfur dioxide may be found free or bound to phenols, for example, gallic acid, aldehydes, and other organic compounds [6].

On the other hand, a high level of this compound brings about toxic effects [7]. As its use is limited by regulation in every country, it is of the utmost importance to develop alternative methods that enable its rapid and cheap determination, for example, using electrochemical techniques [813].

Equilibrium among the different molecular species is reached when $\mathrm{SO}_{2}$ is added to wine. Part reacts with compounds having carbonyl groups and is called bound sulfite, the other part, that in aqueous solution is in equilibrium with bisulfite $\left(\mathrm{HSO}_{3}{ }^{-}\right)$and sulfur dioxide $\left(\mathrm{SO}_{2}\right)$, is called free $\mathrm{SO}_{2}$ (1) $[14,15]$.
The concentration of these species will chiefly depend on $\mathrm{pH}$. Under wine $\mathrm{pH}$ conditions, most free $\mathrm{SO}_{2}$ is present as bisulfite $\left(\mathrm{HSO}_{3}{ }^{-}\right)$:

$$
\begin{gathered}
\mathrm{SO}_{3}{ }^{-2}+\mathrm{H}^{+} \rightleftharpoons \mathrm{HSO}_{3}{ }^{-} \\
\mathrm{HSO}_{3}{ }^{-}+\mathrm{H}^{+} \rightleftharpoons \mathrm{SO}_{2}+\mathrm{H}_{2} \mathrm{O} .
\end{gathered}
$$

Industry employs various methods for determining $\mathrm{SO}_{3}{ }^{-2}$ or $\mathrm{HSO}_{3}{ }^{-}$that are widely used in winemaking, for example, the modified method of optimized Monier-Williams method (2000) [16] (also known as aspiration method) (see Figure 1). Acidification of the sample is the key of the method [17] where the formed $\mathrm{SO}_{2}$ is drawn out by a nitrogen stream. The stream is then reacted with hydrogen peroxide to produce sulfuric acid (2) that is finally titrated with a $0.01 \mathrm{~N}$ $\mathrm{NaOH}$ standard solution. In the current research, this approach is utilized as control method. The procedure eliminates the interferences of pigments and acetic acid:

$$
\mathrm{SO}_{2}+\mathrm{H}_{2} \mathrm{O}_{2} \longrightarrow \mathrm{SO}_{3}{ }^{-2}+\mathrm{H}_{2} \mathrm{O} \longrightarrow \mathrm{H}_{2} \mathrm{SO}_{4} \text {. }
$$




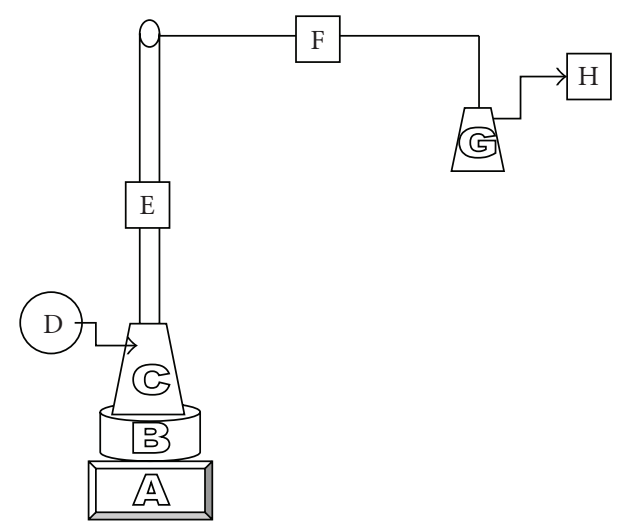

FIgURE 1: Arrangement for the determination of free and bound $\mathrm{SO}_{2}$ by the modified Monier-Williams method. (A) Heater, (B) glycerin bath, (C) flask 1, (D) air pump, (E) refrigerant, (F) connector, $(\mathrm{G})$ flask 2, (H) air output.

Differential pulse voltammetry utilizing the standard addition was the selected electrochemical approach that will be compared to the aspiration method. The standard addition method $[18,19]$ is particularly useful for analyzing complex samples where interference due to the matrix (in real cases) is expected.

\section{Experimental}

2.1. Chemical Reagents. $\mathrm{Na}_{2} \mathrm{SO}_{3}$ (Merck, p.a.), $\mathrm{NaCl}$ (Merck, p.a.), $\mathrm{C}_{6} \mathrm{H}_{2}(\mathrm{OH})_{3} \mathrm{COOH}$ (J.T. Baker), $\mathrm{H}_{2} \mathrm{O}_{2}$ (Vetc, $30 \%$, p.a.), $\mathrm{HCl}$ and (Riedel deHaen, $37 \%$ p.a) (methyl red indicator Sigma-Aldrich, ultrapure $\mathrm{N}_{2}$ (AGA) were used as received.

2.2. Solutions. Fresh $\mathrm{Na}_{2} \mathrm{SO}_{3}$ solutions of different concentrations were prepared employing bidistilled and deionized water. $\mathrm{NaCl}$ about 100 times more concentrated was used as supporting electrolyte. $1 \mathrm{mM} \mathrm{C}_{6} \mathrm{H}_{2}(\mathrm{OH})_{3} \mathrm{COOH}, 0.01 \mathrm{M}$ $\mathrm{NaOH}$ (diluting $0.1 \mathrm{M}$ standard solution), $0.3 \%$ (w/v) $\mathrm{H}_{2} \mathrm{O}_{2}$, and $25 \%(\mathrm{v} / \mathrm{v}) \mathrm{HCl}$ solutions were also prepared.

\subsection{Methods}

\section{Modified Monier-Williams Method}

Determination of Free and Bound Sulfite According to Modified Monier-Williams Method. Free $\mathrm{SO}_{2}$ determination by the aspiration method was conducted as follows. $1 \mathrm{mM}$ sodium sulfite solutions were prepared by weighing and dilution. Ten $20 \mathrm{~mL}$ aliquots of each solution are taken for each set of measurements and solutions were prepared in triplicate. For each measurement, $20 \mathrm{~mL}$ of sample were transferred into flask 1 and then $10 \mathrm{~mL}$ hydrochloric acid $25 \% \mathrm{v} / \mathrm{v}$ were added, and finally the flask was connected to the distillation setup. $10 \mathrm{~mL} 0.3 \%$ hydrogen peroxide and 5 drops of methyl red indicatorwere placed into flask 2. Free $\mathrm{SO}_{2}$ formed in flask 1 was removed by a stream of nitrogen or air at $1 \mathrm{~L} \mathrm{~min}^{-1}$ rate for 20 minutes (a $3 \mathrm{~L} \mathrm{~min}^{-1}$ gas flow afforded
TABLE 1: Free $\mathrm{SO}_{2}$ concentration determined by the MonierWilliams modified method using $1 \mathrm{~L} \mathrm{~min}^{-1}$ air flow.

\begin{tabular}{lcc}
\hline Sample no. & Free $\mathrm{SO}_{2}(\mathrm{ppm})$ & $\begin{array}{c}\text { Free } \mathrm{SO}_{2} \text { applying } \\
\text { correction factor* } \\
(\mathrm{ppm})\end{array}$ \\
\hline 1 & 42,43 & 62,79 \\
2 & 43,59 & 64,52 \\
3 & 45,91 & 67,94 \\
4 & 43,18 & 63,91 \\
5 & 42,84 & 63,41 \\
6 & 45,10 & 66,75 \\
7 & 45,91 & 60,56 \\
8 & 42,92 & 63,52 \\
9 & 42,34 & 62,67 \\
10 & 43,11 & 63,81 \\
11 & 43,46 & 64,32 \\
$*$ Correction factor: $1,48$. &
\end{tabular}

less accurate results). Besides, 30 minutes flow time produced identical results than flushing for 20 minutes). Then, sulfuric acid formed in flask 2 was titrated with $0.01 \mathrm{M} \mathrm{NaOH}$ solution. The end-point is taken by a color change from violet-blue to olive-green. Results obtained using nitrogen or air was identical and consequently all the measurements described here were obtained using air (see Figure 1).

Sulfite concentration was worked out using the equation reported in the literature [20]:

$$
\mathrm{mgL}^{-1} \mathrm{SO}_{2}=\frac{n \times N_{\mathrm{NaOH}} \times 32 \times 1000}{V s},
$$

where $n: \mathrm{NaOH}$ volume used in the titration and Vs: sample volume.

$1 \mathrm{mM}$ sodium sulfite and gallic acid solutions were used for total sulfite determination, and the temperature was kept at $85^{\circ} \mathrm{C}$ throughout the measurement using a glycerin bath. The difference between total and free sulfite corresponds to bound sulfite:

$$
\left.\mathrm{SO}_{2}(\text { total })=\mathrm{SO}_{2} \text { (bound }\right)+\mathrm{SO}_{2} \text { (free) } .
$$

Cyclic Voltammetry and Differential Pulse Voltammetry. A three-compartment cell was utilized. Glassy carbon (geometric area $8.56 \times 10^{-4} \mathrm{~cm}^{2}$ ) was used as working electrode, and a platinum coil of large area was the counter electrode. All potentials quoted in the current work are referred to an $\mathrm{Ag} / \mathrm{AgCl}(3 \mathrm{M} \mathrm{KCl})$ electrode provided with a Luggin capillary tip. Prior to each measurement, the working electrode was washed with distilled water and polished with alumina slurry. The working solution was previously deaerated by flushing with high-purity nitrogen for 10 minutes. A $1 \mathrm{M}$ $\mathrm{NaCl}$ solution, to which $\mathrm{NaOH}$ or $\mathrm{HCl}$ was added to adjust $\mathrm{pH}$, was employed as supporting electrolyte.

Bound-Sulfite Determination by Differential Pulse Voltammetry Using Standard Addition. A cyclic voltammetry study was performed of solutions containing electrolyte and sulfite, 


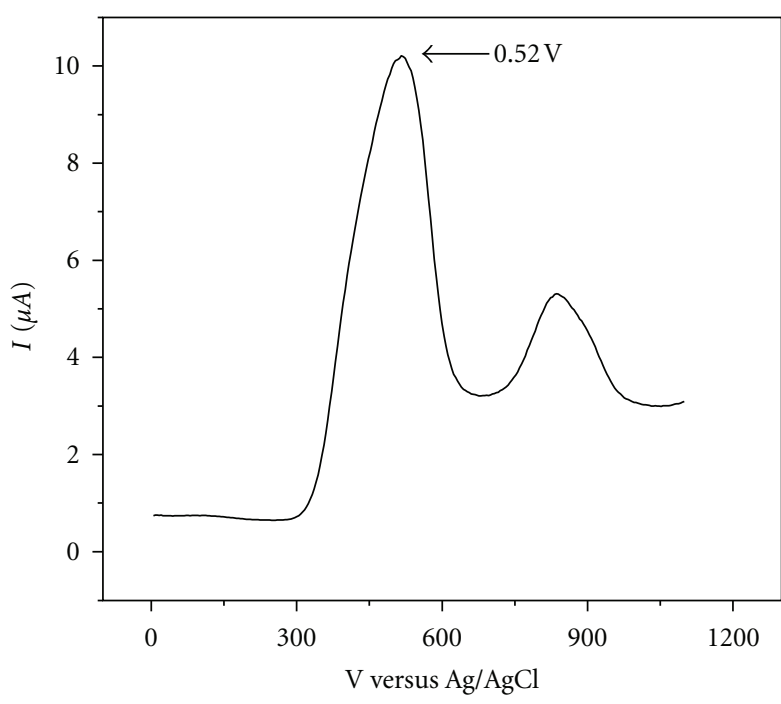

(a)

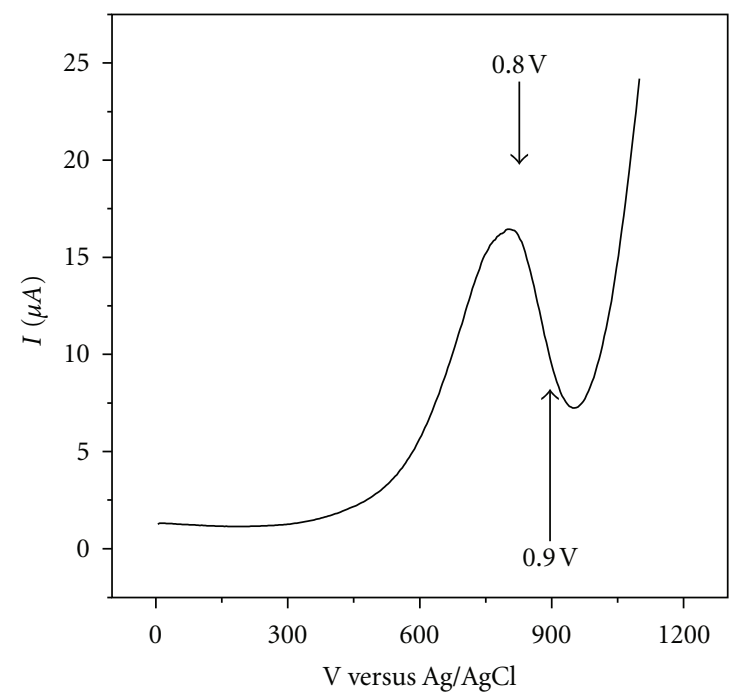

(b)

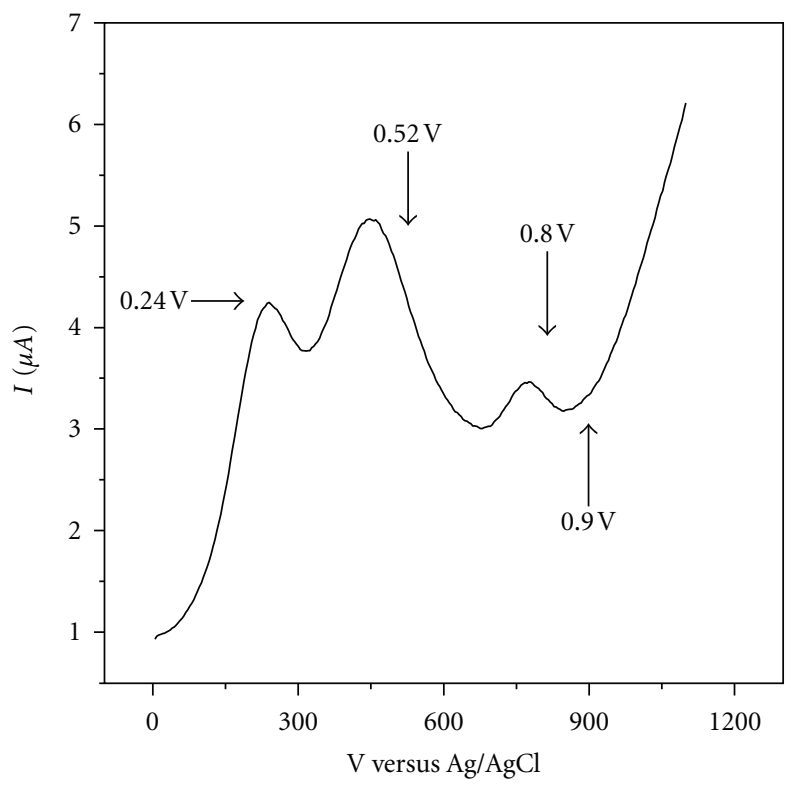

(c)

FIgUre 2: Cyclic voltammetry of (a) $10 \mathrm{mM} \mathrm{SO}_{3}{ }^{-2}$ solution at $\mathrm{pH}$ 9.5. (b) $1 \mathrm{mM}$ gallic acid solution and (c) a gallic acid-sodium sulfite mixture. Initial concentration $10 \mathrm{mM}, \mathrm{pH} 9.5$. Scan rate $0.1 \mathrm{mVs}^{-1}$.

electrolyte and gallic acid, and, also, $10 \mathrm{mM}$ sodium sulfite $+1 \mathrm{mM}$ gallic acid solutions at $\mathrm{pH}$ 9.5. The obtained voltammograms are shown in Figure 2.

Results permit determining the potential at which the current must be measured for obtaining reproducible response related to sulfite concentration.

Measurements were accomplished by mixing $10 \mathrm{~mL}$ $1 \mathrm{mM}$ gallic acid and $10 \mathrm{~mL} 2 \mathrm{mM}$ sodium sulfite solutions. To this solution, ten $2 \mathrm{~mL}$ standard additions of sodium sulfite were performed and the respective voltammograms recorded. With the obtained data, sulfite concentration in the sample was calculated. The same procedure was performed for several samples to obtain a set of data. $\mathrm{No} \mathrm{HCl}$ was added in this case.

\section{Results}

Free sulfite determined by the Monier-Williams modified method is listed in Table 1 (for a set of data).

These results were very reproducible and showed that for a $64 \mathrm{ppm}$ solution, values $c a$. $43 \mathrm{ppm}$ were obtained, very much lower than expected. Thus, the method showed high precision but poor accuracy. To determine if the accuracy problem was due to a too low air flow, unable to remove all $\mathrm{SO}_{2}$, this was increased three times. The obtained values were similar to those in Table 1 but less precise. Besides, the flow time was increased twice as much but no accuracy improvement was observed. On the other hand, it was assumed that the low accuracy could be a temperature problem, because 
TABLE 2: Total $\mathrm{SO}_{2}$ concentration obtained in gallic acid-sulfite solutions by the modified Monier-Williams method.

\begin{tabular}{lc}
\hline Sample no. & Total $\mathrm{SO}_{2} \mathrm{Ppm}$ \\
\hline 1 & 63,63 \\
2 & 63,90 \\
3 & 60,82 \\
4 & 63,63 \\
5 & 62,08 \\
6 & 63,90 \\
7 & 63,13 \\
8 & 63,13 \\
9 & 63,90 \\
10 & 62,32 \\
\hline
\end{tabular}

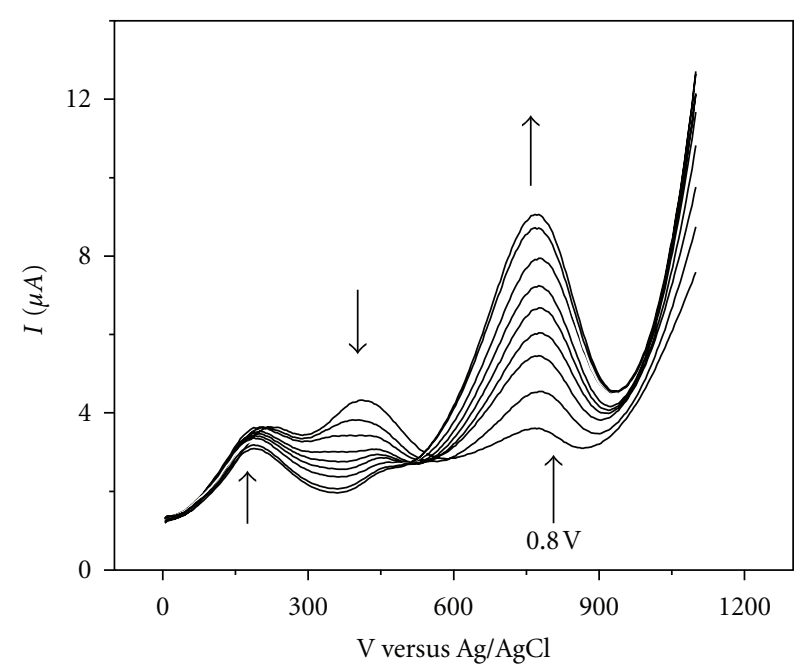

FIGURE 3: Differential pulse voltammetry profile of a gallic acidsulfite mixture using standard addition method (ten 2-mL sulfite solution additions). Sulfite and gallic acid initial concentration $2 \mathrm{mM}$ and $1 \mathrm{mM}$, respectively.

total sulfite measured in the presence of gallic acid at $85^{\circ} \mathrm{C}$ showed good accuracy. Consequently, the experiments were repeated at $85^{\circ} \mathrm{C}$. The found results were close to those illustrated in Table 1 but accompanied by a precision loss. These results are surprising since the described method appears in the literature as a very accurate one for free-sulfite determination [16]. Measurements were also accomplished using nitrogen instead of air, but the problem remained the same. Therefore, it was decided to apply a correction factor to the measurements generating thus Table 1 third column. Finally, the low accuracy was ascribed to a likely factor related to $\mathrm{SO}_{2}$ loss that would be generated in flask 1, during the acidification step, before the connection to the distillation arrangement was accomplished. This problem would not arise with bound sulfite owing to adduct formation that would stabilize sulfite at room temperature. In the winemaking business, this drawback would not exist because sulfite is always in contact with adduct-forming substances with various degree of stability at room temperature. However, it is a factor to be considered for sulfite determination in
TABLE 3: $\mathrm{Na}_{2} \mathrm{SO}_{3}$ determination by DPV.

\begin{tabular}{ll}
\hline Sample no. & $\mathrm{Na}_{2} \mathrm{SO}_{3}(\mathrm{M})$ \\
\hline 1 & $1.97 \times 10^{-3}$ \\
2 & $2.13 \times 10^{-3}$ \\
3 & $1.85 \times 10^{-3}$ \\
4 & $2.07 \times 10^{-3}$ \\
5 & $1.98 \times 10^{-3}$ \\
6 & $2.14 \times 10^{-3}$ \\
7 & $1.85 \times 10^{-3}$ \\
\hline Correction factor: 109 &
\end{tabular}

Correction factor: 1.09 .

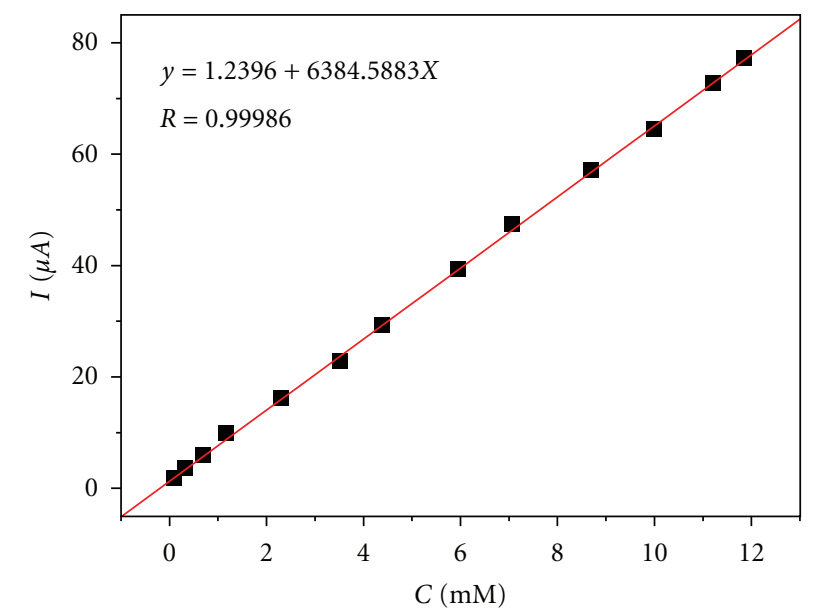

FIGURE 4: Calibration curve of sulfur determined by differential pulse voltammetry using standard addition.

samples containing no "sulfite-ligands." In such a case, the system design should be modified by adding a third mouth to flask 1 for in situ acidification with the air flow already circulating.

Applying 1.48 as correction factor, Table 1 statistical analysis [18] produced the following data:

$$
\begin{gathered}
\bar{x}=64.02 \mathrm{ppm} \text { free } \mathrm{SO}_{2}, \\
S=1.98 \\
\mathrm{CV}=3.1 \% \\
\mu=64.02 \pm 1.33
\end{gathered}
$$

The method became accurate and reproducible by using a previously constructed calibration curve to determine the correction factor.

Total sulfite determination results using the modified Monier-Williams method are included in Table 2.

Statistical analysis of Table 2 afforded the following data:

$$
\begin{gathered}
\bar{x}=63.05 \mathrm{ppm} \text { total } \mathrm{SO}_{2}, \\
S=0.96 \\
\mathrm{CV}=1.53 \% \\
\mu=63.05 \pm 0.68 .
\end{gathered}
$$


TABLE 4

\begin{tabular}{|c|c|c|c|c|}
\hline Technique & LOD & Concentration range & Method & Reference \\
\hline DPV & $0.3 \mathrm{uM}$ & $0.6-100 \mu \mathrm{M}$ & $\begin{array}{l}\text { Oxidation of sulfite by ferrocenedicarboxylic acid } \\
\text { modified multiwall carbon nanotube paste electrode }\end{array}$ & {$[10]$} \\
\hline $\begin{array}{l}\text { Flow injection } \\
\text { analysis (FIA) }\end{array}$ & $0.4 \mathrm{mg} / \mathrm{L}$ & $0.5-50 \mathrm{mg} \mathrm{L}^{-1}$ & $\begin{array}{l}\text { Pervaporation-Flow injection with amperometric } \\
\text { detection (Cooper hexacyanoferrate-carbon nanotube } \\
\text { modified carbon paste electrode) }\end{array}$ & {$[12]$} \\
\hline Amperometry & $\begin{array}{l}1.58 \mathrm{mg} / \mathrm{L} \\
47.5 \mu \mathrm{M}\end{array}$ & $3.85-33.8 \mathrm{mg} \mathrm{L}^{-1}$ & $\begin{array}{l}\text { Reduction of bisulfite by iron aminopolypyridyl } \\
\text { conducting-glassy carbon modified electrode }\end{array}$ & {$[11]$} \\
\hline $\begin{array}{l}\text { Cyclic } \\
\text { voltammetry }\end{array}$ & $1.26 \mathrm{mg} / \mathrm{L}$ & $0.4-70 \mathrm{mg} \mathrm{L}^{-1}$ & $\begin{array}{l}\text { Reduction of } \mathrm{SO}_{2} \text { by porphyrin-nafion/composite } \\
\text { modified glassy carbon electrode }\end{array}$ & {$[13]$} \\
\hline $\begin{array}{l}\text { DVP using } \\
\text { standard addition }\end{array}$ & $7.2 \mathrm{mg} / \mathrm{L}$ & $10-40 \mathrm{mg} \mathrm{L}^{-1}$ & Oxidation of sulfite at glassy carbon electrodes & This work \\
\hline
\end{tabular}

It can be clearly seen that the method works well with good accuracy and precision. A correction factor was not necessary in this case.

It seems that, as will be seen later, adduct formation between sulfite and gallic acid avoids losses by shifting equilibrium 1 to the left, preventing thus $\mathrm{SO}_{2}$ evaporation before the measurement starts.

As for electrochemical analysis, the voltammetric results (Figure 2) suggested that the signal appearing at $0.25 \mathrm{~V}$ for the gallic acid-sulfite mixture points to the formation of a new species, since this peak was not observed in the voltammograms of each separate analyte. The signal at $0.55 \mathrm{~V}$ would correspond to the first gallic acid oxidation, and the signal at $0.8 \mathrm{~V}$ would be mainly due to sulfite. This assignment was inferred by simple comparison of the three voltammograms.

Quantitation employing the standard addition method was achieved by measuring the current at two potentials, namely, 0.8 and $0.9 \mathrm{~V}$. The later one yielded the best results. Figure 3 shows the obtained differential pulse voltammograms.

Results obtained by this technique with current measured at $0.9 \mathrm{~V}$ are presented in Table 3. Each result corresponds to a set of 10 measurements of a $2 \mathrm{mM}$ sodium sulfite solution using the standard addition approach.

Statistical analysis of Table 3 yielded the following data:

$$
\begin{gathered}
\bar{x}=2.00 \times 10^{-3} \mathrm{M}, \\
S=1.2 \times 10^{-4}, \\
\mathrm{CV}=10.5 \%, \\
\mu=2.00 \pm 1.12 \times 10^{-3} .
\end{gathered}
$$

The method proved to be appropriate, accurate, and reproducible. Similar results were obtained for free-sulfite utilizing the same method (not shown). In both cases, it is mandatory to construct a calibration curve to determine the correction factor, which is usually close to 1 .

Finally, the method was tested by varying sulfite concentration in the range usually employed in wines [20]. Excellent linear regression and detection limit low enough to become a suitable method for wines (see Figure 4) were obtained. From this figure, a linear range between 10 and $40 \mathrm{mg}$ of sulfur per liter and a detection limit $7.2 \mathrm{mg} \mathrm{L}^{-1}$ can be inferred.

It is noteworthy that the obtained linear range can be extended to higher concentrations (not reported in the current work because they are outside the limits of sulfite found in wines). Compared to other methods (Table 4), although the reported here is not the best regarding to detection limit, it is very interesting indeed because of its low cost and because it requires neither sophisticated equipment nor modified electrodes, being very easy to implement on an industrial scale.

\section{Conclusions}

Differential pulse voltammetry using standard addition is a reproducible approach to determine sulfite in the presence and absence of gallic acid by measuring the current at $0.9 \mathrm{~V}$. Previously, a calibration curve must be drawn to quantify the correction factor to be applied to current values.

The modified Monier-Williams method is suitable for the determination of total sulfite when working in the presence of gallic acid.

In the case of free-sulfite in samples that contain no substances that strongly interact with sulfite or bisulfite, it is necessary to modify flask 1 design and to acidify in situ.

\section{Acknowledgments}

The authors acknowledge financial support from Anillo ACT 24 project, 3100066 Fondecyt project, Puente PUC 04/2011 project, and Dicyt-USACH project.

\section{References}

[1] C. S. Ough and E. A. Crowell, "Use of sulfur dioxide in winemaking," Journal of Food Science, vol. 52, pp. 386-389, 1987.

[2] L. A. Sayavedra-Soto and M. W. Montgomery, "Inhibition of polyphenoloxidase by sulfite," Journal of Food Science, vol. 51, pp. 1531-1536, 1986.

[3] F. W. Beech, L. F. Burroughs, C. F. Timberlake, and G. C. Whiting, "Progrès récents sur l'aspect chimique et l'action anti-microbienne de l'anhydride sul- fureux $\left(\mathrm{SO}_{2}\right)$," Bulletin de l'OIV, vol. 52, pp. 1001-1022, 1979. 
[4] P. Romano and G. Suzzi, Wine Microbiology and Biotechnology, Harwood Academic Publishers, Chur, Switzerland, 1993.

[5] L. C. Schroeter, Sulfur Dioxide, Applications in Foods, Beverages and Pharmaceuticals, Pergamon Press Inc., Oxford, UK, 1st edition, 1966.

[6] I. Hornsey, The Chemistry and Biology of Winemaking, Thomas Graham House, 2007.

[7] H. J. Schwartz, "Sensitivity to ingested metabisulfite: variations in clinical presentation," Journal of Allergy and Clinical Immunology, vol. 71, no. 5, pp. 487-489, 1983.

[8] M. Scampicchio, N. S. Lawrence, A. Arecchi, and S. Mannino, "Determination of sulfite in wine by linear sweep voltammetry," Electroanalysis, vol. 20, no. 4, pp. 444-447, 2008.

[9] A. Isaac, C. Livingstone, A. J. Wain, R. G. Compton, and J. Davis, "Electroanalytical methods for the determination of sulfite in food and beverages," Trends in Analytical Chemistry, vol. 25, no. 6, pp. 589-598, 2006.

[10] A. A. Ensafi and H. Karimi-Maleh, "Ferrocenedicarboxylic acid modified multiwall carbon nanotubes paste electrode for voltammetric determination of sulfite," International Journal of Electrochemical Science, vol. 5, no. 3, pp. 392-406, 2010.

[11] C. García, C. Domínguez, A. Aliaga et al., "Electrochemical properties of a conducting film derived from iron(II) tris(diaminopolypyridyl) complex in the S(IV) oxoanions reduction," Electroanalysis, vol. 23, no. 6, pp. 1401-1409, 2011.

[12] L. S. T. Alamo, T. Tangkuaram, and S. Satienperakul, "Determination of sulfite by pervaporation-flow injection with amperometric detection using copper hexacyanoferrate-carbon nanotube modified carbon paste electrode," Talanta, vol. 81, no. 4-5, pp. 1793-1799, 2010.

[13] K. Calfumán, M. García, M. J. Aguirre, B. Matsuhiro, L. Mendoza, and M. Isaacs, "Electrochemical reduction of S(IV) compounds in water-ethanol solutions at Nafion/tetraruthenated porphyrins glassy carbon modified electrodes," Electroanalysis, vol. 22, no. 3, pp. 338-344, 2010.

[14] J. C. Barbe, G. de Revel, A. Joyeux, A. Lonvaud-Funel, and A. Bertrand, "Role of carbonyl compounds in $\mathrm{SO}_{2}$ binding phenomena in musts and wines from botrytized grapes," Journal of Agricultural and Food Chemistry, vol. 48, no. 8, pp. 3413$3419,2000$.

[15] I. Streeter, A. J. Wain, J. Davis, and R. G. Compton, "Cathodic reduction of bisulfite and sulfur dioxide in aqueous solutions on copper electrodes: an electrochemical ESR study," Journal of Physical Chemistry B, vol. 109, no. 39, pp. 18500-18506, 2005.

[16] "Monier-Williams AOAC official method (optimized method) 990.28," in AOAC Official Methods of Analysis, chapter 47, pp. 29-30, 200.

[17] B. Zoecklein, K. Fugelsang, and B. F. Gump Nury, Análisis y Producción de Vino, A. S. Acribia, 2001.

[18] D. Skoog, D. West, and J. Holler, Fundamentos de Química Analitica, Thomson, 8th edition, 2005.

[19] D. Skoog, J. Holler, and T. Nieman, Principios de Análisis Instrumental, McGraw-Hill, New York, NY, USA, 5th edition, 2001.

[20] E. Bordeu and J. Scarpa, Análisis Químico del Vino, Universidad Católica de Chile, Santiago, Chile, 2000. 


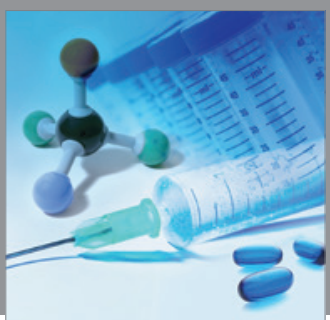

International Journal of

Medicinal Chemistry

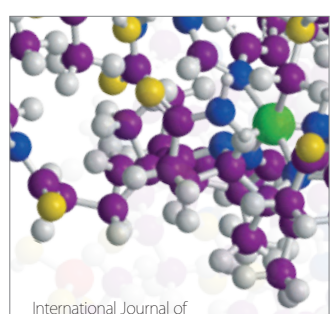

Carbohydrate Chemistry

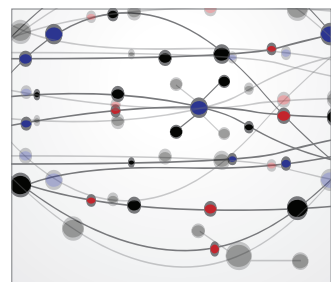

The Scientific World Journal
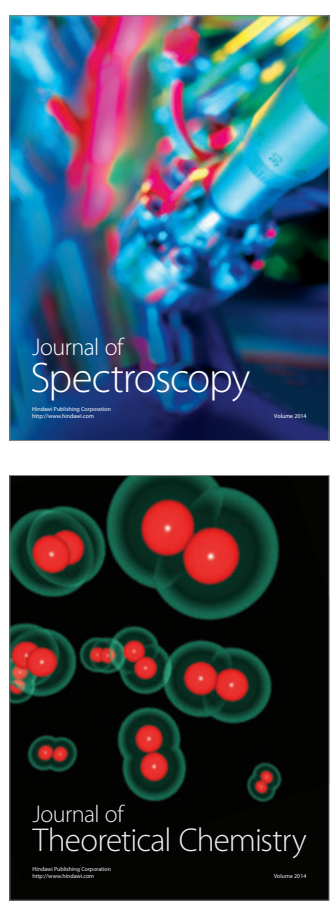
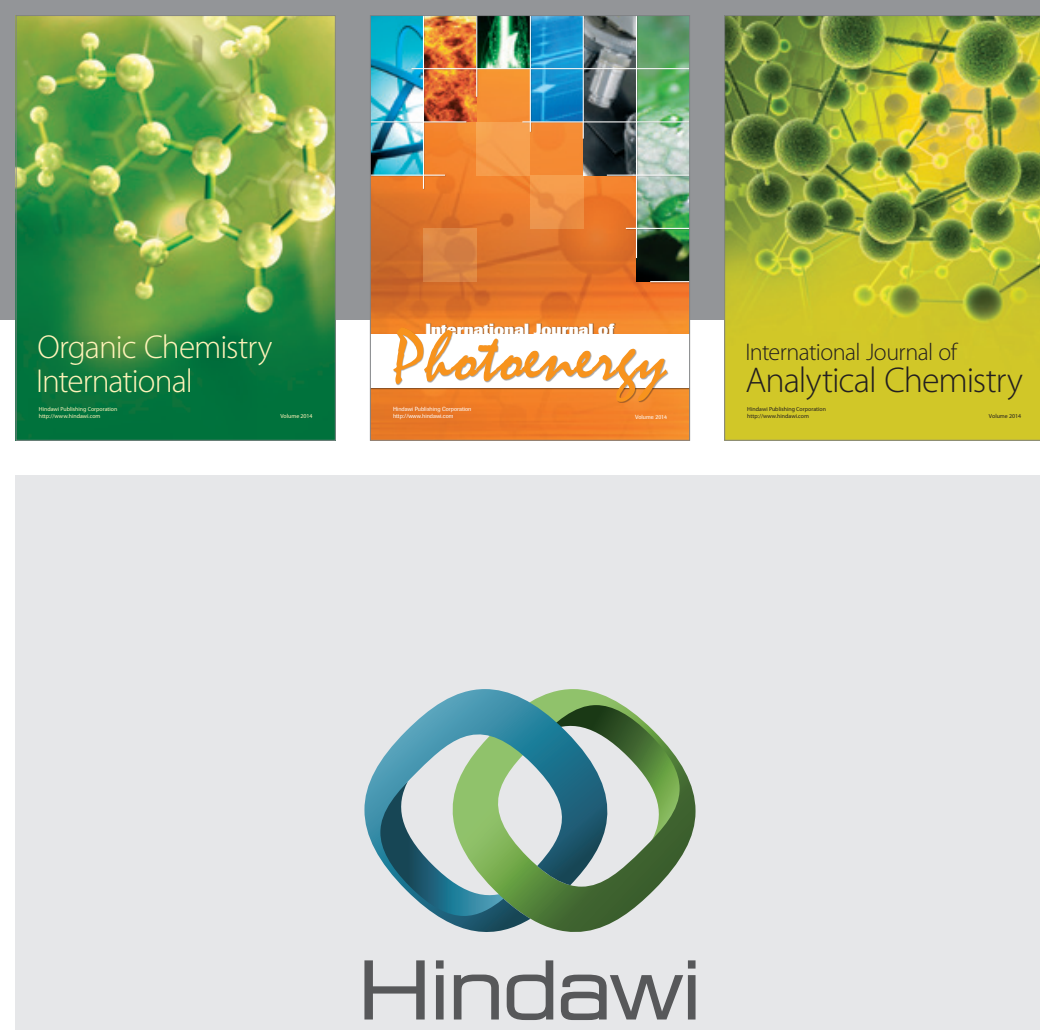

Submit your manuscripts at

http://www.hindawi.com
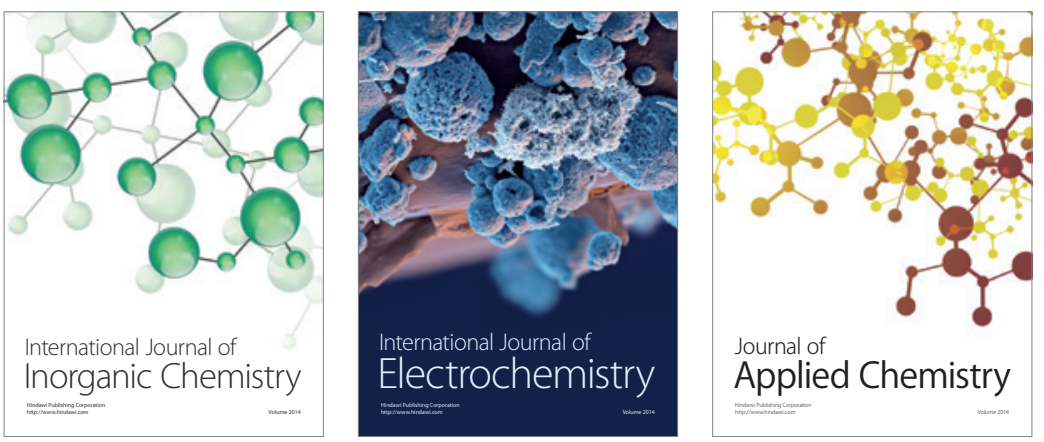

Journal of

Applied Chemistry
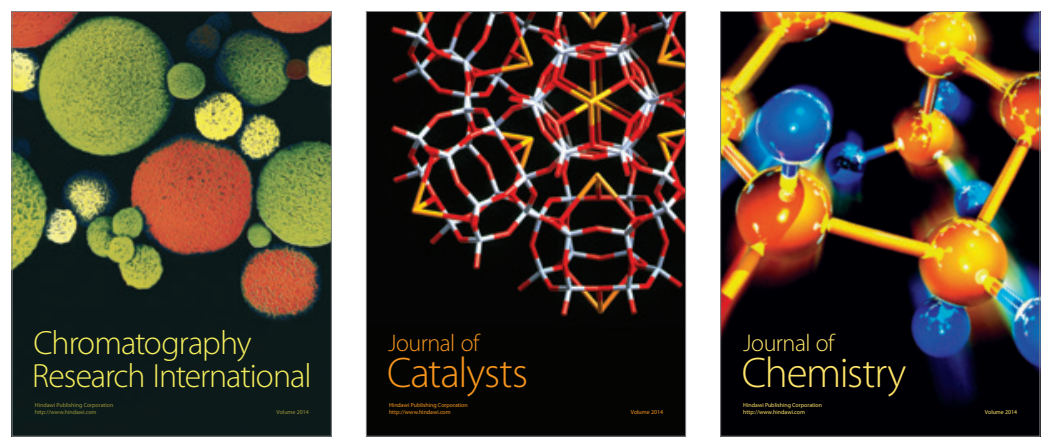
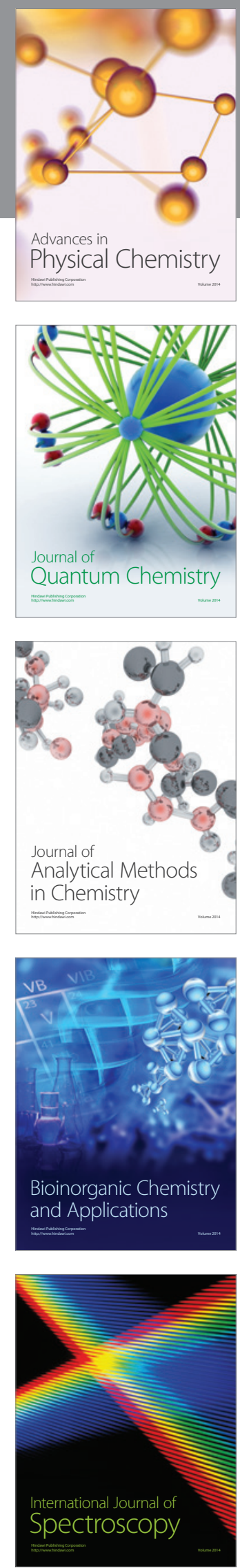